\title{
Clinical significance of altered S100A2 expression in gastric cancer
}

\author{
YING ZHAO $^{1}$, TIAN-BIAO ZHANG ${ }^{2}$ and QIANG WANG ${ }^{1}$ \\ ${ }^{1}$ Department of General Surgery, Shengjing Hospital of China Medical University, Shenyang, Liaoning 110004; \\ ${ }^{2}$ Department of Biochemistry and Molecular Biology, College of Basic Medicine, China Medical University, \\ Heping, Shenyang, Liaoning 110001, P.R. China
}

Received October 30, 2012; Accepted December 18, 2012

DOI: $10.3892 / o r .2013 .2236$

\begin{abstract}
The S100A2 gene has been reported to be a putative tumor-suppressor gene. Nevertheless, overexpression of S100A2 has been found in certain types of cancer. This study investigated S100A2 expression in tissue specimens of gastritis, intestinal metaplasia, adenomatous dysplasia and gastric cancer to determine its association with clinical features. A serial of tissue samples (gastritis, intestinal metaplasia, adenomatous dysplasia and gastric cancer samples) were used for quantitative real-time reverse transcriptasepolymerase chain reaction (qRT-PCR), western blotting and immunohistochemical analyses of S100A2 expression. The data revealed that there was a gradual loss of S100A2 expression from gastritis, intestinal metaplasia and dysplasia to cancer tissue specimens $(\mathrm{P}<0.001)$. In gastric cancer samples, loss of S100A2 expression was associated with increased tumor size, depth of invasion, lymph node metastasis and a poor prognosis $(\mathrm{P}<0.001)$. However, the intestinal type of gastric cancer expressed more S100A2 protein than the diffuse type $(\mathrm{P}<0.001)$. In conclusion, data from the present study demonstrated that loss of S100A2 expression contributes to gastric cancer development and progression; therefore, the determination of S100A2 expression levels may help to predict the carcinogenesis and aggressiveness of gastric cancer as well as patient survival.
\end{abstract}

\section{Introduction}

Although there has been a sharp decline in both the worldwide incidence and mortality due to gastric cancer during the second half of the 20th century, gastric cancer continues to be a major health issue (1). To date, surgery is the most

Correspondence to: Professor Qiang Wang, Department of General Surgery, Shengjing Hospital of China Medical University, Shenyang, Liaoning 110004, P.R. China

E-mail: f2046@163.com

Key words: gastric cancer, S100A2, gene expression, prognosis, disease progression common treatment method, whereas chemotherapy to treat gastric cancer has a limited success rate as this cancer is not particularly sensitive to chemotherapeutic drugs. Thus, early detection is the key to successful treatment to ensure the long-term survival of patients since it is impossible to completely surgically resect gastric cancer in the advanced stage. The risk factors of gastric cancer include Helicobacter pylori infection, consumption of smoked foods, salted fish and meat and pickled vegetables, as well as obesity, tobacco smoke, chronic gastritis and blood type A. These risk factors alter the expression and function of critical cell growth-related genes. Therefore, it is important to develop novel strategies for the prevention, treatment, and prediction of prognosis of gastric cancer. In addition, understanding the molecular mechanisms responsible for gastric cancer development and progression will help to identify useful biomarkers to predict disease progression or provide a means to prevent or delay this disease from occurring.

To this end, the family of S100 proteins is involved in the regulation of various cellular processes, such as cell cycle progression and cell differentiation. S100 proteins are localized in the cytoplasm and/or nucleus of a wide range of cells, and they include 25 members clustering on human chromosome 1q21, whose encoding proteins contain two EF-hand calcium-binding motifs. Each member contains two EF-hands connected by a central hinge, which are S100 family-specific in the N-terminus and canonical in the C-terminus. Among these proteins, $11-\mathrm{kDa}$ acidic S100A2 is directly involved in protein phosphorylation, cell cycle regulation, growth, motility, differentiation, survival and chemoattraction (2). The S100A2 promoter has been shown to be transcriptionally activated by wild-type p53, but not by mutated p53, suggesting that S100A2 is a p53 target gene $(3,4)$. Previous studies have demonstrated the loss of S100A2 expression in breast cancer and several other types of cancer (2). Indeed, ectopic overexpression of S100A2 suppressed oral squamous cancer cells to grow, migrate, invade in Matrigel, and form colonies in soft agar or grow tumors in nude mice (5). In contrast, knockdown of S100A2 expression restrained head and neck cancer cell migration (6). However, other studies have shown the opposite effect; for example, S100A2 overexpression has been detected in pancreatic carcinoma (7), non-small cell lung carcinomas (8) and thyroid carcinoma (9). Therefore, the aim of this study was to further clarify the association 
between S100A2 expression and clinicopathological data. We determined the expression of S100A 2 mRNA and protein in a large number of gastric cancer and precancerous lesions and then associated its expression with clinical significance in gastric cancer.

\section{Materials and methods}

Study population and pathological diagnosis. In the present study, we collected gastric cancer tissues from gastrectomy, gastric biopsies from gastritis, and gastric intestinal metaplasia (IM) and adenoma from endoscopy from patients at Department of Surgery, Shengjing Hospital of China Medical University between January 1995 and January 2005. None of the patients underwent chemotherapy, radiotherapy, or adjuvant treatment before surgery. The tissue specimens were routinely fixed in $10 \%$ neutral formalin, embedded in paraffin, and cut into 4- $\mu \mathrm{m}$ section. These sections were then stained with hematoxylin and eosin (H\&E) to carry out the pathological diagnosis. In addition, part of the tissue samples was snap-frozen in liquid nitrogen and then stored at $-80^{\circ} \mathrm{C}$ for later protein extraction and RNA isolation. The tumor-nodemetastasis (TNM) stage for each gastric cancer specimen was evaluated according to the Union Internationale Contre le Cancer (UICC) system for the extent of tumor spread (10). Histological architecture of gastric cancer was expressed in terms of Lauren's classification $(11,12)$. In this study, we also included additional clinicopathological data, such as tumor size, depth of invasion, and lymphatic and venous invasion. In addition, lymphatic and venous invasion of gastric cancer cells was diagnosed using H\&E staining and D2-40 immunostaining and EvG staining, respectively. The Ethics Committee of China Medical University approved our research protocol, and each patient or their guardian provided a consent form for participation in this study. The patients were followed up through their medical records and telephone conversations.

Quantitative real-time reverse transcriptase-polymerase chain reaction $(q R T-P C R)$. Total RNA was extracted from tissue specimens using TRIzol reagent (Invitrogen, Carlsbad, CA, USA) according to the manufacturer's instructions. These RNA samples were reversely transcribed into cDNA using RevertAid $^{\mathrm{TM}}$ reverse transcriptase (Takara, Dalian, China). Real-time PCR was then performed using these cDNA samples in an ABI PRISM 7500 Sequence Detection system (Applied Biosystems, Foster City, CA, USA), and the qPCR conditions were $50^{\circ} \mathrm{C}$ for $2 \mathrm{~min}$ and $95^{\circ} \mathrm{C}$ for $10 \mathrm{~min}$, followed by 50 cycles of $95^{\circ} \mathrm{C}$ for $15 \mathrm{sec}$, and $60^{\circ} \mathrm{C}$ for $1 \mathrm{~min}$. The primers for GAPDH (135 bp, 201-335, NM_002046.3) were 5'-CAATGACCCCTTCATTGACC-3' (sense) and 5'-TG GAAGATGGTGATGGGATT-3' (antisense). The primers for S100A2 (140 bp, 440-579, NM_005978.3) were 5'-GAAGGA ACTTCTGCACAAGG-3' (sense) and 5'-GTGCCAGGAAA ACAGCATAC-3' (antisense). GAPDH mRNA was used as an internal control for loading and handling of samples. Each assay was performed in triplicate, the average was then calcu-

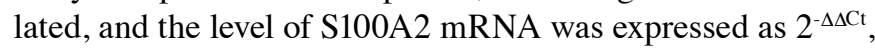
where $\Delta \mathrm{Ct}=\mathrm{Ct}(\mathrm{S} 100 \mathrm{~A} 2)-\mathrm{Ct}(\mathrm{GAPDH})$ and $\Delta \Delta \mathrm{Ct}=\Delta \mathrm{Ct}$ (carcinoma) - $\Delta \mathrm{Ct}$ (adjacent non-neoplastic mucosa).
Protein extraction and western blot analysis. Protein was extracted from tissue samples using a homogenizer in RIPA lysis buffer. These protein samples were concentrated using the BAC method (Bio-Rad Laboratories, Hercules, CA, USA). After denaturation, the protein samples were separated by electrophoresis on an SDS-polyacrylamide gel (15\% acrylamide) and then transferred onto Hybond membranes (Amersham, Freiburg, Germany). The membranes were then incubated overnight at $4^{\circ} \mathrm{C}$ in 5\% skim milk in TBS-T $(10 \mathrm{mM}$ Tris- $\mathrm{HCl}$, $150 \mathrm{mM} \mathrm{NaCl}$ and $0.1 \%$ Tween 20). For immunoblotting, the membrane was then incubated for $1 \mathrm{~h}$ with a rabbit antibody against S100A2 (Abcam, Cambridge, UK; 1:500). After rinsing with TBS-T, the membrane was further incubated with an anti-rabbit or anti-mouse IgG conjugated to horseradish peroxidase (Dako, Carpinteria, CA, USA) at a dilution of 1:1,000 for $1 \mathrm{~h}$. Then, positive protein bands were visualized by incubating the membrane with ECL-Plus detection reagents (Santa Cruz Biotechnology, Santa Cruz, CA, USA) and exposed to X-ray film (Fuji, Japan). Next, the membrane was washed with WB Stripping Solution (pH 2.0-3.0; Nacalai, Tokyo, Japan) for $1 \mathrm{~h}$, and then the western blot procedures were repeated for detection of GAPDH protein expression using an anti-GADPH antibody from Sigma (St. Louis, MO, USA) at a dilution of 1:10,000 as an internal control antibody. Densitometric quantification of S100A2 protein expression in gastric samples was performed using Scion Image software (Scion Corp., Frederick, MD, USA) and was compared to GADPH levels.

Tissue microarray (TMA) and immunohistochemistry. Representative areas of gastric lesions were first identified in H\&E-stained sections, and a 2-mm diameter tissue core per donor block was punched out and transferred into a recipient block, with a maximum of 48 cores per block using a manual arraying device (MTA-1; Beecher Instruments Inc., Sun Prairie, WI, USA). After being re-embedded into the paraffin blocks, $4-\mu \mathrm{m}$ consecutive sections were incised from the recipient blocks and mounted onto polylysinecoated glass slides. After confirmation with H\&E staining, these TMA sections were used for immunohistochemistry experiments.

For the immunohistochemistry experiments, the sections were first deparaffinized in xylene and rehydrated through graded concentrations of alcohol. The sections were then subjected to blockage of endogenous peroxidase activity in $1.5 \%$ hydrogen peroxide/methanol at room temperature for $10 \mathrm{~min}$ and subjected to antigen retrieval using a microwave oven (Oriental Rotor Ltd., Co., Tokyo, Japan) and retrieval solution (Target Retrieval Solution; Dako, Carpinteria, CA, USA) for $15 \mathrm{~min}$. Next, the sections were incubated with a rabbit polyclonal S100A2 antibody at a dilution of 1:200 for $1 \mathrm{~h}$ at room temperature. After washing three times with TBS-T, the sections were further incubated with an anti-rabbit IgG antibody conjugated to horseradish peroxidase (Dako) at a dilution of 1:1,000 for $1 \mathrm{~h}$. The final color was visualized by exposing the sections to $0.5 \mathrm{mg} / \mathrm{ml} \mathrm{3,3'-diaminobenzidine} \mathrm{and}$ $0.005 \%$ hydrogen peroxide for $\sim 5 \mathrm{~min}$. After counterstaining with Mayer's hematoxylin, the sections were dehydrated, cleared and mounted. Negative control sections were incubated with TBS-T instead of the primary antibody. 

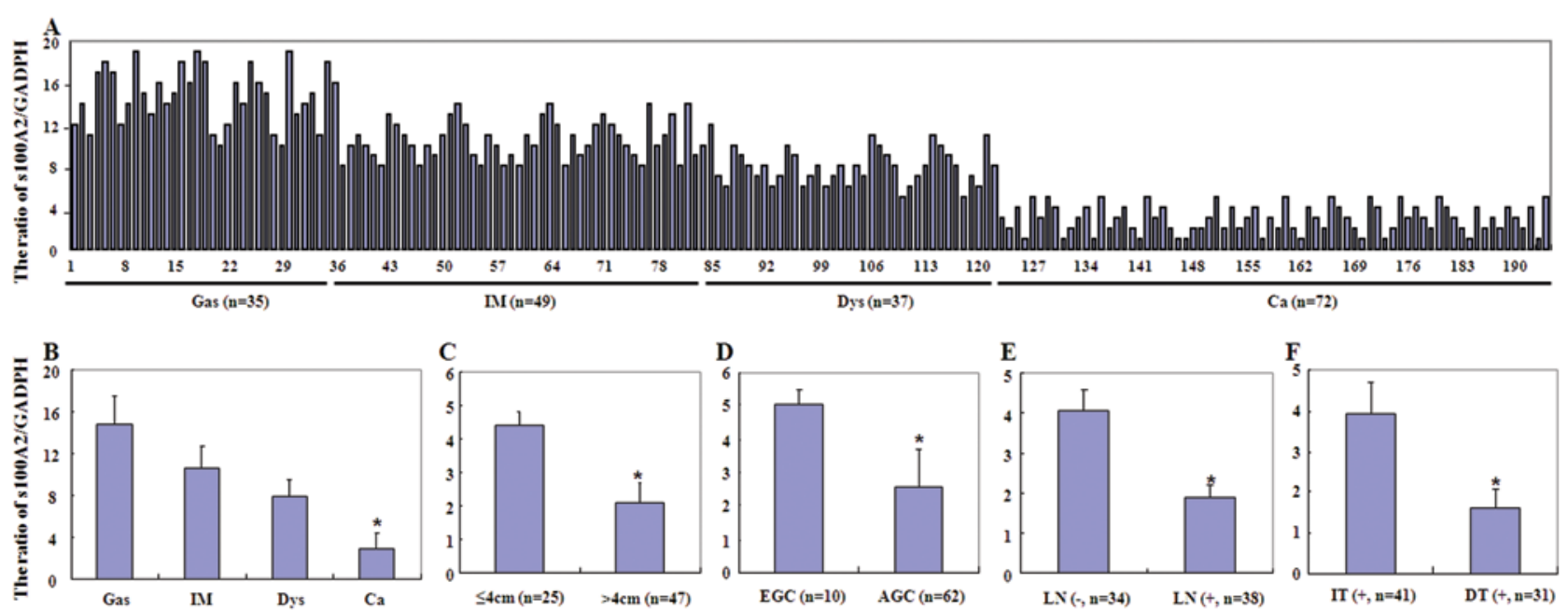

Figure 1. (A) qRT-PCR detection of S100A2 mRNA expression in different gastric tissue specimens to determine its association with clinicopathological features of gastric cancer. (B) Levels of S100A2 mRNA gradually decreased from gastritis (Gas), intestinal metaplasia (IM) and dysplasia (Dys) to carcinoma (Ca) samples $(\mathrm{P}<0.001)$. Lower S100A2 mRNA expression was associated with (C) a larger tumor size, (D) deeper invasive depth, (E) frequent lymph node metastasis and (F) non-intestinal type of cancer. EGC, early gastric cancer; AGC, advanced gastric cancer; LN, lymph node metastasis; IT, intestinal type; DT, diffuse type.

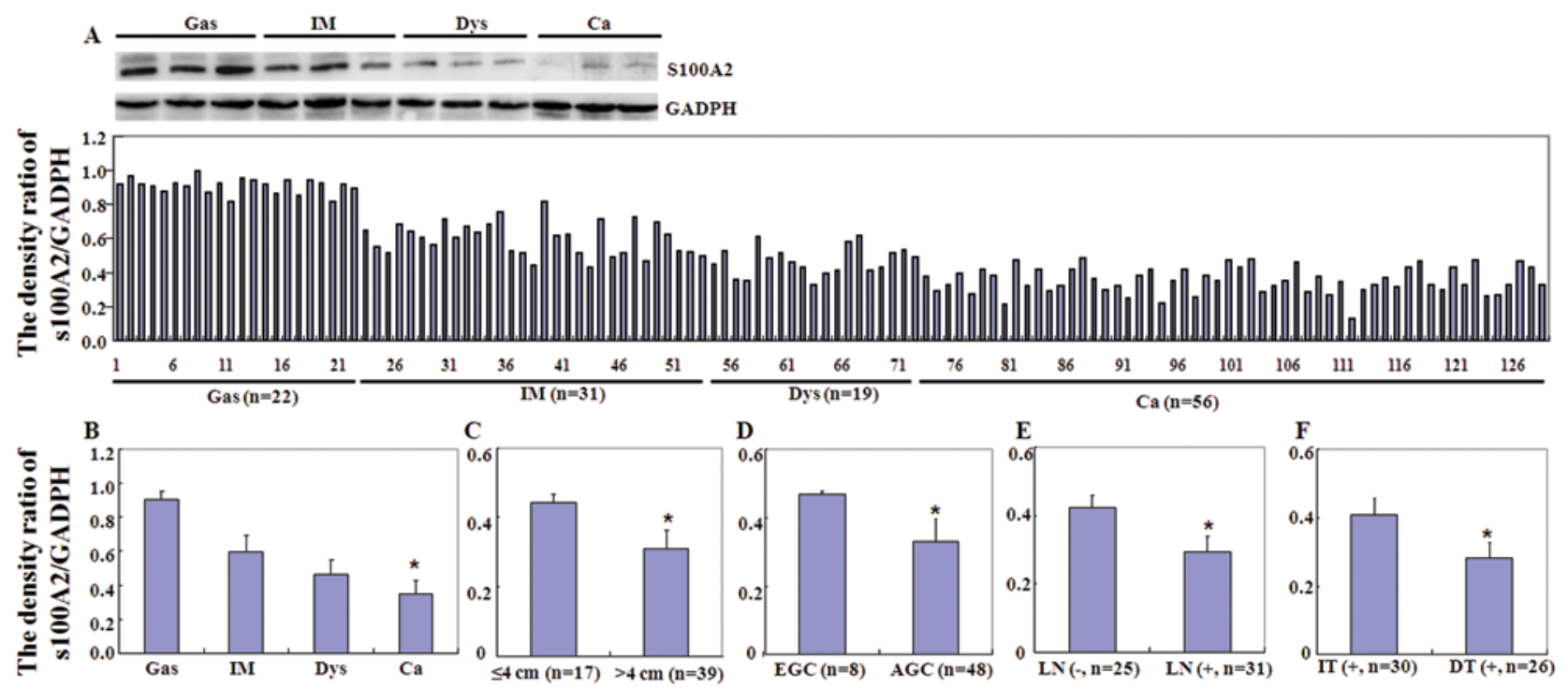

Figure 2. Expression of S100A2 protein in different gastric tissue specimens to determine its association with clinicopathological features of gastric cancer. (A) Western blot analysis. Tissue lysate was loaded and probed with the anti-S100A2 antibody (upper panel, $29 \mathrm{kDa}$ ) or GAPDH antibody (lower panel, $37 \mathrm{kDa}$ ). Densitometric analysis was performed, and the data indicated that S100A2 protein was detectable in gastritis (Gas), intestinal metaplasia (IM), dysplasia (Dys) and carcinoma samples. (B) The S100A2 expression level gradually decreased from gastritis (Gas), intestinal metaplasia (IM), and dysplasia (Dys) to carcinoma (Ca) samples $(\mathrm{P}<0.001)$. Lower S100A2 protein expression was associated with (C) a larger tumor size, (D) deeper invasive depth, (E) frequent lymph node metastasis, and (F) non-intestinal type of cancer. EGC, early gastric cancer; AGC, advanced gastric cancer; LN, lymph node metastasis; IT, intestinal type; DT, diffuse type.

The stained TMA sections were subsequently reviewed and scored by two experienced pathologists without any knowledge of the clinicopathological data. For each tissue core, the number of cells positively staining for S100A2 was counted in five fields at a magnification of $\mathrm{x} 200$. The percentage of positively stained cells was calculated and scored as follows: $0-5 \%$, negative (-); 6-25\%, weakly positive (+); $26-50 \%$, moderately positive $(++)$; and $>50 \%$, strongly positive $(+++)$. Finally, these two scores were combined to indicate the semi-quantitative expression of S100A2 protein, i.e., -, +, ++ and +++.
Statistical analysis. Spearman's correlation test was performed to analyze the rank data, and the Student's t-test was used to compare the means of different groups. Kaplan-Meier survival plots were generated, and comparisons between survival curves were tested using log-rank analysis. Cox's proportional hazards model was employed for multivariate analysis. SPSS 10.0 software (SPSS Inc., Chicago, IL, USA) was used to generate all statistical data, and $\mathrm{P}<0.05$ was considered to indicate a statistically significant result. 


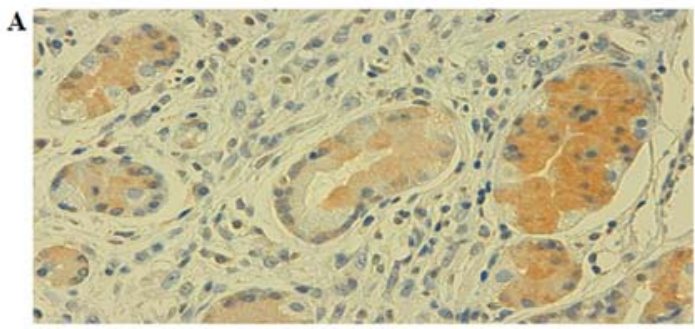

Gastritis

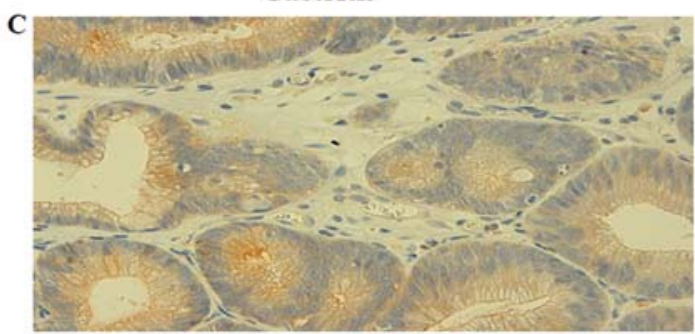

Adenoma

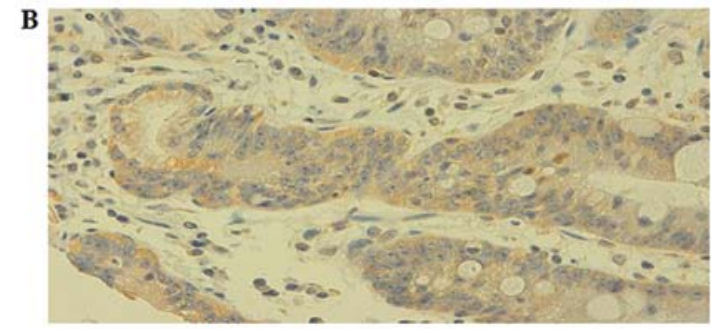

Intestinal metaplasia

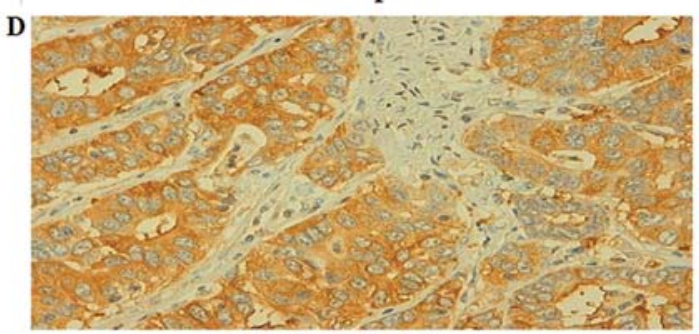

Adenocarcinoma

Figure 3. Immunohistochemical staining of S100A2 protein in different gastric lesions. S100A2 protein was positively expressed in the cytoplasm of (A) gastritis, (B) intestinal metaplasia, (C) adenomatous dysplasia and (D) cancer tissues.

Table I. Differential expression of S100A2 protein in gastric tissue specimens.

\begin{tabular}{lrrrrrrr}
\hline & & \multicolumn{3}{c}{ S100A2 protein expression level } & & \\
\cline { 3 - 6 } Group & $\mathrm{n}$ & - & + & ++ & +++ & PR (\%) & P-value \\
\hline Gastritis & 73 & 0 & 16 & 21 & 36 & 100.0 & $<0.001$ \\
Intestinal metaplasia & 86 & 8 & 8 & 16 & 54 & 90.7 & \\
Adenoma & 63 & 17 & 5 & 15 & 26 & 73.0 & \\
Gastric cancer & 348 & 178 & 92 & 66 & 12 & 48.9 & \\
\hline
\end{tabular}

-, negative (0-5\%); +, weakly positive (6-25\%); ++, moderately positive (26-50\%); +++, strongly positive (>50\%). PR, positive rate.

\section{Results}

In the present study, we first assessed S100A2 mRNA levels using qRT-PCR in a subset of gastric tissue specimens. Reduced expression of S100A2 mRNA was observed from gastritis, intestinal metaplasia and dysplasia to cancer tissue samples ( $\mathrm{P}<0.001$, Fig. 1). Loss of S100A2 mRNA expression occurred more frequently in gastric cancer with a larger tumor size, deeper invasive depth and lymph node metastasis and in intestinal-type carcinoma $(\mathrm{P}<0.05)$. Similar data were also observed for S100A2 protein expression in these samples analyzed by western blot analysis (Fig. 2).

We immunostained the tissue samples for S100A2 expression and found that S100A2 protein was positively expressed in the cytoplasm of the gastric epithelial cells and in the intestinal metaplasia, adenomatous dysplasia, and carcinoma tissues (Fig. 3). Specifically, S100A2 protein was expressed in all 73 cases of gastritis, 90.7\% (78/86) of intestinal metaplasia, $73.0 \%$ (46/63) of adenomatous dysplasia, and $48.9 \%(170 / 348)$ of gastric cancer tissues. There was a statistically significant difference in the level of the S100A2 protein between gastritis, intestinal metaplasia, and dysplasia samples and cancer tissues $(\mathrm{P}<0.001$, Table I). In gastric cancer, the expression of S100A2 protein was frequently absent in younger patients compared to that of older patients $(\mathrm{P}<0.05)$, and $\mathrm{S} 100 \mathrm{~A} 2$ expression was inversely associated with tumor size, depth of invasion, lymphatic and venous invasion, lymph node metastasis and TNM stage $(\mathrm{P}<0.05)$. S100A2 protein was also more highly expressed in the intestinal type of gastric cancer than in the diffuse type $(\mathrm{P}<0.05)$. However, S100A2 expression was not associated with patient gender $(\mathrm{P}>0.05$; Table II).

Next, we assessed the association of S100A2 protein expression with the survival of the gastric cancer patients. Survival data were available for all 348 gastric cancer patients with a follow-up period ranging from 1 month to 10.1 years (median, 65.1 months). Fig. 4 indicates that loss of S100A2 expression contributed to poorer survival of the gastric cancer patients $(\mathrm{P}<0.05)$. Kaplan-Meier analysis demonstrated that the cumulative survival rate of patients with weak and moderate S100A2 expression was obviously higher than those with loss of S100A2 expression. Moreover, multivariate analyses revealed that S100A2 expression, depth of invasion, lymphatic invasion, venous invasion, lymph node metastasis, distant metastasis, and TNM stage were independent predictors for gastric cancer patient survival. 
Table II. Association of S100A2 protein expression with the clinicopathological features of the gastric cancer patients.

\begin{tabular}{|c|c|c|c|c|c|c|c|}
\hline \multirow[b]{2}{*}{ Clinicopathological features } & \multirow[b]{2}{*}{$\mathrm{n}$} & \multicolumn{4}{|c|}{ S100A2 protein expression level } & \multirow[b]{2}{*}{ PR $(\%)$} & \multirow[b]{2}{*}{ P-value } \\
\hline & & - & + & ++ & +++ & & \\
\hline Age (years) & & & & & & & 0.013 \\
\hline$<55$ & 139 & 81 & 36 & 18 & 4 & 41.7 & \\
\hline$\geq 55$ & 209 & 97 & 56 & 48 & 8 & 53.6 & \\
\hline Gender & & & & & & & 0.697 \\
\hline Male & 248 & 127 & 67 & 50 & 4 & 48.8 & \\
\hline Female & 100 & 51 & 25 & 16 & 8 & 49.0 & \\
\hline Tumor size $(\mathrm{cm})$ & & & & & & & 0.005 \\
\hline$\leq 4$ & 120 & 48 & 42 & 20 & 10 & 60.0 & \\
\hline$>4$ & 228 & 130 & 50 & 46 & 2 & 43.0 & \\
\hline Depth of invasion & & & & & & & 0.032 \\
\hline $\mathrm{T}_{\mathrm{is}}-\mathrm{T}_{1}$ & 33 & 13 & 8 & 6 & 6 & 60.5 & \\
\hline $\mathrm{T}_{2}-\mathrm{T}_{4}$ & 315 & 165 & 84 & 60 & 6 & 47.6 & \\
\hline Lymphatic invasion & & & & & & & $<0.001$ \\
\hline- & 192 & 70 & 68 & 47 & 7 & 63.5 & \\
\hline+ & 156 & 108 & 24 & 19 & 5 & 30.8 & \\
\hline Venous invasion & & & & & & & $<0.001$ \\
\hline- & 245 & 105 & 79 & 56 & 5 & 57.1 & \\
\hline+ & 103 & 73 & 13 & 10 & 7 & 29.1 & \\
\hline Lymph node metastasis & & & & & & & $<0.001$ \\
\hline- & 138 & 14 & 64 & 52 & 8 & 89.9 & \\
\hline+ & 210 & 164 & 28 & 14 & 4 & 21.9 & \\
\hline TNM stage & & & & & & & $<0.001$ \\
\hline I & 6 & 1 & 3 & 2 & 0 & 83.3 & \\
\hline II & 60 & 15 & 25 & 16 & 4 & 75.0 & \\
\hline III & 104 & 46 & 30 & 24 & 4 & 55.8 & \\
\hline IV & 178 & 116 & 34 & 24 & 4 & 34.8 & \\
\hline Lauren's classification & & & & & & & $<0.001$ \\
\hline Intestinal-type & 203 & 62 & 81 & 51 & 9 & 69.0 & \\
\hline Diffuse-type & 145 & 116 & 92 & 66 & 12 & 20.0 & \\
\hline
\end{tabular}

-, negative $(0-5 \%) ;+$, weakly positive $(6-25 \%) ;++$, moderately positive $(26-50 \%) ;+++$, strongly positive $(>50 \%)$. PR, positive rate.

\section{Discussion}

In the present study, we analyzed the expression of S100A2 mRNA and protein in gastritis, intestinal metaplasia, adenomatous dysplasia, and gastric cancer tissue specimens to determine whether the expression levels were associated with clinical features. We found that S100A2 protein was observed in the cytoplasm of gastric tissue specimens, which confirmed previous data (13), whereas we did not find nuclear localization of S100A2 protein, which was previously observed in oral and esophageal mucosa $(5,14)$. Our data demonstrated that expression of S100A2 mRNA and protein gradually decreased from gastritis, intestinal metaplasia and adenomatous dysplasia to gastric cancer.

A previous study showed that S100A2 was expressed in tissue specimens of patients with benign prostate hyperplasia, while it was reduced in prostate cancer (15). Another study reported that expression of S100A2 mRNA was positive in $77.5 \%$ of esophageal squamous cell carcinoma tissues, which was lower than that in normal mucosa (100\%) detected by in situ hybridization (16). However, normal esophageal mucosa expressed S100A2 in the cell nuclei, whereas twothirds of Barrett's dysplasia and adenocarcinoma samples with S100A2 expression had stronger cytosolic staining of S100A2 protein (14). An additional study demonstrated that 2 out of $8(25 \%)$ esophageal cancer cell lines and 14 out of $30(47 \%)$ primary esophageal squamous cell carcinomas exhibited S100A2 expression compared to paired normal tissues (17), suggesting that S100A2 maybe related to the progression of esophageal squamous cell carcinoma. In the present study, we found gradually reduced expression of S100A2 from gastritis, intestinal metaplasia and dysplasia to carcinoma. We believe 
Table III. Multivariate analysis of clinicopathological variables for survival of the gastric cancer patients.

\begin{tabular}{lcr}
\hline Clinicopathological parameter & Relative risk $(95 \%$ CI) & P-value \\
\hline Age $(\geq 65$ years) & $1.674(0.921-1.921)$ & 0.061 \\
Gender (female) & $0.793(0.495-1.029)$ & 0.082 \\
Depth of invasion $\left(\mathrm{T}_{2}-\mathrm{T}_{4}\right)$ & $4.218(2.689-6.329)$ & 0.003 \\
Lymphatic invasion $(+)$ & $1.521(1.053-2.359)$ & 0.049 \\
Venous invasion $(+)$ & $1.635(1.163-2.503)$ & 0.042 \\
Lymph node metastasis $(+)$ & $2.091(1.194-3.808)$ & 0.022 \\
Distant metastasis $(+)$ & $4.102(2.659-6.243)$ & $<0.001$ \\
TNM stage (III-IV) & $5.876(2.792-12.566)$ & $<0.001$ \\
Lauren's classification (IT/DT) & $1.210(0.883-1.699)$ & 0.364 \\
S100A2 expression $(+-+++)$ & $1.522(1.725-3.122)$ & 0.039 \\
\hline
\end{tabular}

CI, confidence interval; TNM, tumor node metastasis; IT, intestinal-type; DT, diffuse-type.

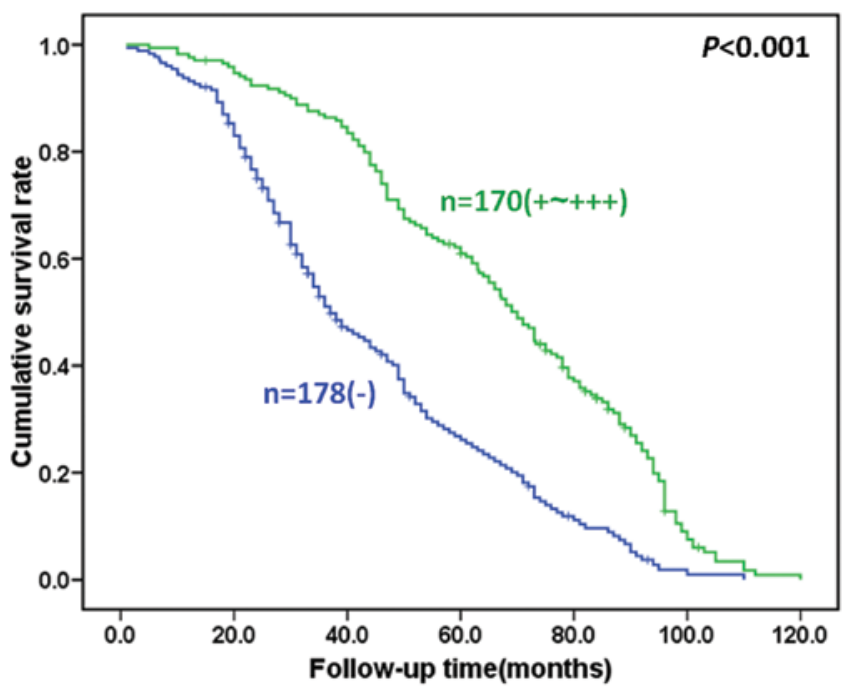

Figure 4. Association of S100A2 protein expression with the prognosis of gastric carcinoma patients. Kaplan-Meier curves for cumulative survival rate of patients with gastric cancer were plotted against S100A2 protein expression levels.

that our tissues covered a series of lesions throughout gastric cancer development, and a gradual loss of S100A2 expression in these specimens indicates that S100A2 is associated with carcinogenesis. Indeed, a previous study revealed that intestinal metaplasia is an adaptive condition for an injured gastric epithelium, and inflammation can develop into globoid dysplasia and then to gastric signet ring cell carcinoma, as shown by morphological appearance and biological characteristics (18). Moreover, pathological and genetic observations of intestinal dysplasia have demonstrated that gastric dysplasia is a premalignant lesion that has a high probability of undergoing malignant transformation (19). Thus, our data, for the first time, demonstrated that loss of S100A2 expression may contribute to gastric carcinogenesis. Other studies have shown that loss of S100A2 expression is only due to promoter hypermethylation (20-22).
Furthermore, the present data revealed that expression of S100A2 mRNA and protein was inversely linked to tumor size, depth of tumor invasion, lymphatic and venous invasion, lymph node metastasis, and TNM stage; these findings are supported by other studies in various types of cancer (23-25). These findings suggest that S100A2 plays a role in the suppression of growth, invasion and metastasis of gastric cancer. However, the function of S100A2 may be tissue-specific. For example, in esophageal cancer, the level of S100A2 mRNA expression has been shown to be closely associated with de-differentiation and lymph node metastasis (16), while positive S100A2 expression has been significantly associated with lymphatic invasion in lung cancer (26). In contrast, Nagy et al (6) showed that S100A2 has a clear inhibitory effect on cell motility by antisense oligonucleotides and extracellular treatments. Furthermore, Tsai et al reported that ectopic expression of S100A2 in the human malignant squamous cell carcinoma cell line KB resulted in significant inhibition of proliferation, migration and invasion. Moreover, S100A2 significantly reduced the number of colonies formed in semi-solid agar and decreased tumor growth and burden in nude mice with oral squamous cancer (5). Taken altogether, we speculate that downregulation of S100A2 expression is involved in the development and progression of gastric cancer.

Although gastric cancer originates from the same gastric epithelium, its morphological features vary substantially for individual patients. According to Lauren's classification, intestinal-type gastric cancer is characterized by cohesive carcinoma cells forming gland-like tubular structures with an expanding or infiltrative growth pattern, which includes well and moderately differentiated adenocarcinoma $(11,12)$. In contrast, diffuse-type gastric cancer displays less apparent adenocarcinoma or lacks cell adhesion and contains poorly differentiated and signet ring cell carcinoma $(11,12)$. The present data demonstrated that the expression of S100A2 mRNA and protein was higher in intestinal-type gastric cancer than in diffuse-type, suggesting that S100A2 may contribute to the development of diffuse-type gastric cancer but does not play a role in intestinal-type. A previous study 
showed that S100A2 is more highly expressed in well and moderately differentiated cancer than in poorly differentiated gastric cancer (13), which supports the present data.

To date, there have been no reports describing the prognostic significance of S100A2 expression in gastric cancer. Our present study showed that S100A2 expression was associated with a more favorable prognosis of gastric cancer patients. Multivariate analysis using Cox's proportional risk analysis indicated that depth of invasion, lymphatic or venous invasion, lymph node metastasis, distal metastasis, TNM stage, and S100A2 expression were independent factors for the prognosis of carcinoma patients. These findings suggest that $\mathrm{S} 100 \mathrm{~A} 2$ is an independent prognostic factor for gastric cancer. Others have reported that reduced or increased expression of S100A2 is an independent predictive factor, depending on the type of human cancer (27-30). Nevertheless, the data from our present study using a large number of tissue samples, demonstrated the clinical significance of S100A2 expression. Further studies will investigate how the S100A2 gene contributes to suppression of gastric cancer development and progression.

\section{Acknowledgements}

This study was supported, in part, by a grant from the Natural Science Foundation of Liaoning Province (\#201202279).

\section{References}

1. Jemal A, Bray F, Center MM, Ferlay J, Ward E and Forman D: Global cancer statistics. CA Cancer Clin 61: 69-90, 2011.

2. Wolf S, Haase-Kohn C and Pietzsch J: S100A2 in carcinogenesis: a friend or a foe? Amino Acids 41: 849-861, 2011.

3. Mueller A, Schäfer BW, Ferrari S, Weibel M, Makek M, Höchli $\mathrm{M}$ and Heizmann CW: The calcium-binding protein S100A2 interacts with p53 and modulates its transcriptional activity. J Biol Chem 280: 29186-29193, 2005.

4. Lapi E, Iovino A, Fontemaggi G, Soliera AR, Iacovelli S, Sacchi A, Rechavi G, Givol D, Blandino G and Strano S: S100A2 gene is a direct transcriptional target of p53 homologues during keratinocyte differentiation. Oncogene 25: 3628-3637, 2006.

5. Tsai ST, Jin YT, Tsai WC, Wang ST, Lin YC, Chang MT and Wu LW: S100A2, a potential marker for early recurrence in early-stage oral cancer. Oral Oncol 41: 349-357, 2005.

6. Nagy N, Brenner C, Markadieu N, Chaboteaux C, Camby I, Schäfer BW, Pochet R, Heizmann CW, Salmon I, Kiss R and Decaestecker C: S100A2, a putative tumor suppressor gene, regulates in vitro squamous cell carcinoma migration. Lab Invest 81: 599-612, 2001.

7. Ohuchida K, Mizumoto K, Miyasaka Y, Yu J, Cui L, Yamaguchi H, Toma H, Takahata S, Sato N, Nagai E, Yamaguchi K, Tsuneyoshi M and Tanaka M: Over-expression of S100A2 in pancreatic cancer correlates with progression and poor prognosis. J Pathol 213: 275-282, 2007.

8. Bartling B, Rehbein G, Schmitt WD, Hofmann HS, Silber RE and Simm A: S100A2-S100P expression profile and diagnosis of non-small cell lung carcinoma: impairment by advanced tumour stages and neoadjuvant chemotherapy. Eur J Cancer 43 1935-1943, 2007

9. Ito Y, Yoshida H, Tomoda C, Uruno T, Miya A, Kobayashi K, Matsuzuka F, Kakudo K, Kuma K and Miyauchi A: Expression of S100A2 and S100A6 in thyroid carcinomas. Histopathology 46: 569-575, 2005.

10. Sobin LH and Wittekind CH: TNM Classification of Malignant Tumors. 6th edition. Hoboken NJ (ed). John Wiley \& Sons, NJ, 2002.

11. Zheng HC, Li XH, Hara T, Masuda S, Yang XH, Guan YF and Takano Y: Mixed-type gastric carcinomas exhibit more aggressive features and indicate the histogenesis of carcinomas. Virchows Arch 452: 525-534, 2008.
12. Zheng H, Takahashi H, Murai Y, Cui Z, Nomoto K, Miwa S, Tsuneyama K and Takano Y: Pathobiological characteristics of intestinal and diffuse-type gastric carcinoma in Japan: an immunostaining study on the tissue microarray. J Clin Pathol 60: 273-277, 2007.

13. Luo J, Zhu Y, Yang G, Gong L, Wang B and Liu H: Loss of Reprimo and S100A2 expression in human gastric adenocarcinoma. Diagn Cytopathol 39: 752-757, 2007.

14. Lee OJ, Hong SM, Razvi MH, Peng D, Powell SM, Smoklin M, Moskaluk CA and El-Rifai W: Expression of calcium-binding proteins S100A2 and S100A4 in Barrett's adenocarcinomas. Neoplasia 8: 843-850, 2006.

15. Kwon YW, Chang IH, Kim KD, Kim YS, Myung SC, Kim MK and Kim TH: Significance of S100A2 and S100A4 expression in the progression of prostate adenocarcinoma. Korean J Urol 51: 456-462, 2010

16. Cao LY, Yin Y, Li H, Jiang Y and Zhang HF: Expression and clinical significance of S100A2 and p63 in esophageal carcinoma. World J Gastroenterol 15: 4183-4188, 2009.

17. Imazawa M, Hibi K, Fujitake S, Kodera Y, Ito K, Akiyama S and Nakao A: S100A2 overexpression is frequently observed in esophageal squamous cell carcinoma. Anticancer Res 25: 1247-1250, 2005

18. Zheng HC, Xu XY, Yu M, Takahashi H, Masuda S and Takano Y: The role of Reg IV gene and its encoding product in gastric carcinogenesis. Hum Pathol 41: 59-69, 2010.

19. Zhang YC: Geographic pathology of gastric dysplasia in China. Semin Surg Oncol 10: 100-106, 1994

20. Wicki R, Franz C, Scholl FA, Heizmann CW and Schäfer BW: Repression of the candidate tumor suppressor gene S100A2 in breast cancer is mediated by site-specific hypermethylation. Cell Calcium 22: 243-254, 1997.

21. Rehman I, Cross SS, Catto JW, Leiblich A, Mukherjee A, Azzouzi AR, Leung HY and Hamdy FC: Promoter hypermethylation of calcium binding proteins S100A6 and S100A2 in human prostate cancer. Prostate 65: 322-330, 2005.

22. Feng G, Xu X, Youssef EM and Lotan R: Diminished expression of S100A2, a putative tumor suppressor, at early stage of human lung carcinogenesis. Cancer Res 61: 7999-8004, 2001

23. Zhang X, Hunt JL, Shin DM and Chen ZG: Down-regulation of S100A2 in lymph node metastases of head and neck cancer. Head Neck 29: 236-243, 2007.

24. Suzuki F, Oridate N, Homma A, Nakamaru Y, Nagahashi T, Yagi K, Yamaguchi S, Furuta Y and Fukuda S: S100A2 expression as a predictive marker for late cervical metastasis in stage I and II invasive squamous cell carcinoma of the oral cavity. Oncol Rep 14: 1493-1498, 2005.

25. Matsumoto K, Irie A, Satoh T, Ishii J, Iwabuchi K, Iwamura M, Egawa S and Baba S: Expression of S100A2 and S100A4 predicts for disease progression and patient survival in bladder cancer. Urology 70: 602-607, 2007.

26. Matsubara D, Niki T, Ishikawa S, Goto A, Ohara E, Yokomizo T, Heizmann CW, Aburatani H, Moriyama S, Moriyama H, Nishimura Y, Funata N and Fukayama M: Differential expression of S100A2 and S100A4 in lung adenocarcinomas: clinicopathological significance, relationship to p53 and identification of their target genes. Cancer Sci 96: 844-857, 2005.

27. Almadori G, Bussu F, Galli J, Rigante M, Lauriola L, Michetti F, Maggiano N, Schafer BW, Heizmann CW, Ranelletti FO and Paludetti G: Diminished expression of S100A2, a putative tumour suppressor, is an independent predictive factor of neck node relapse in laryngeal squamous cell carcinoma. J Otolaryngol Head Neck Surg 38: 16-22, 2009.

28. Lauriola L, Michetti F, Maggiano N, Galli J, Cadoni G, Schäfer BW, Heizmann CW and Ranelletti FO: Prognostic significance of the $\mathrm{Ca}(2+)$ binding protein $\mathrm{S} 100 \mathrm{~A} 2$ in laryngeal squamous-cell carcinoma. Int J Cancer 89: 345-349, 2000.

29. Wang H, Zhang Z, Li R, Ang KK, Zhang H, Caraway NP, Katz RL and Jiang F: Overexpression of S100A2 protein as a prognostic marker for patients with stage I non-small cell lung cancer. Int J Cancer 116: 285-290, 2005.

30. Kyriazanos ID, Tachibana M, Dhar DK, Shibakita M, Ono T, Kohno $\mathrm{H}$ and Nagasue N: Expression and prognostic significance of S100A2 protein in squamous cell carcinoma of the esophagus. Oncol Rep 9: 503-510, 2002. 